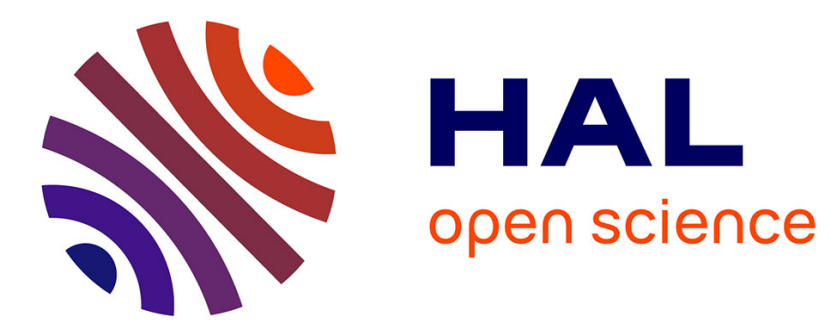

\title{
Investigation of electrooptic modulation from organic-inorganic crystals
}

Jean-Paul Salvestrini, Julien Zaccaro, Alain Ibanez, Marc Fontana

\section{To cite this version:}

Jean-Paul Salvestrini, Julien Zaccaro, Alain Ibanez, Marc Fontana. Investigation of electrooptic modulation from organic-inorganic crystals. Applied Physics B - Laser and Optics, 1998, 67 (6), pp.761-763. 10.1007/s003400050578. hal-00186039

\section{HAL Id: hal-00186039 \\ https://hal.science/hal-00186039}

Submitted on 10 Jan 2022

HAL is a multi-disciplinary open access archive for the deposit and dissemination of scientific research documents, whether they are published or not. The documents may come from teaching and research institutions in France or abroad, or from public or private research centers.
L'archive ouverte pluridisciplinaire HAL, est destinée au dépôt et à la diffusion de documents scientifiques de niveau recherche, publiés ou non, émanant des établissements d'enseignement et de recherche français ou étrangers, des laboratoires publics ou privés.

\section{다)(1) $(5$}

Distributed under a Creative Commons Attribution - NonCommercial| 4.0 International 


\title{
Investigation of electrooptic modulation from organic-inorganic crystals
}

\author{
J.P. Salvestrini ${ }^{1}$, J. Zaccaro ${ }^{2}$, A. Ibanez $^{2}$, M.D. Fontana ${ }^{1}$ \\ ${ }^{1}$ Laboratoire Matériaux Optiques à Propriétés Spécifiques, C.L.O.E.S., Université de Metz et Supelec, 2 rue E. Belin, 57078 Metz Cedex, France \\ (Fax: +33-3/87-75-96-01, E-mail: salvestr@ese-metz.fr; fontana@ese-metz.fr) \\ ${ }^{2}$ Laboratoire de Cristallographie associé à l'Université J. Fourrier (Grenoble I), CNRS, BP 166, 38042 Grenoble Cedex 09, France \\ (Fax: +33-4/76-88-10-38, E-mail: zaccaro@labs.polycnrs-gre.fr; ibanez@labs.polycnrs-gre.fr)
}

\begin{abstract}
This paper presents the first investigation of the characteristics of organic-inorganic crystals for a possible use in electrooptic devices. Electrooptic and dielectric properties in an electric field of frequency varying from $1 \mathrm{kHz}$ to $1 \mathrm{MHz}$ applied along the $c$-axis were determined in 2-amino5-nitropyridinum dihydrogenphosphate (2A5NPDP) and 2amino-5-nitropyridinum dihydrogenarsenate (2A5NPDAs) around room temperature at a wavelength of $633 \mathrm{~nm}$. The values of the thermooptic coefficients are also given. The whole set of properties are discussed in terms of figures of merit and compared to those of other crystals used for electrooptic modulation of a laser beam.
\end{abstract}

PACS: 78.20.Jq; 78.20.Nv; 78.20.-e

The search for new materials with a large nonlinear optical response (NLO) which can be incorporated in efficient devices is of much current interest. It is established that each family of materials, i.e. inorganic crystals, such as KDP, KTP or $\mathrm{LiNbO}_{3}$, or organic molecular crystals such as NPP, possesses some advantages and inconveniences [1].

A new approach was recently proposed that attempts to combine the advantages of organic and inorganic families. The crystal engineering of these new NLO materials is based on the anchorage of organic molecules exhibiting a large NLO efficiency on mineral groups which insure convenient thermal, mechanical stabilities but also a high optical damage threshold. The synthesis and crystal growth of these organic-inorganic phases is now wellcontrolled in many cases [2-4]. Among them, 2-amino5-nitropyridinum dihydrogenphosphate (2A5NPDP) and 2amino-5-nitropyridinum dihydrogenarsenate (2A5NPDAs) were synthesized and shown to be suitable for applications in frequency conversion [5].

These two compounds are isomorphous with close cell parameters (space group Pna2 $2_{1}$ ). The mineral subnetwork is built up from polar layers of $\left[\mathrm{H}_{2} \mathrm{XO}_{4}^{-}\right]_{\mathrm{n}}(\mathrm{X}=\mathrm{P}$, As) parallel to the $(b, c)$ plane. The organic molecules are anchored to these planes through three short hydrogen bonds in a herring bone motif. The axis of the molecules mainly lies in the $(a, c)$ plane with a reduced angle $\left(\approx 36^{\circ}\right)$ with respect to the twofold $c$-axis $[6,7]$.

The 2A5NPDP and 2A5NPDAs hybrid salts are synthesized from dissolution of the 2A5NP molecule in aqueous $\mathrm{H}_{3} \mathrm{XO}_{4}(\mathrm{X}=\mathrm{P}, \mathrm{As})$ acidic solutions. Their crystal growth is carried out in solution using the standard temperature reduction method [3]. Thus, large (several $\mathrm{cm}^{3}$ ) and optically clear crystals have been grown. Their good crystal quality was confirmed by X-ray diffraction topography. The improved mechanical stability of these hybrid crystals, compared to the corresponding organic molecular crystals (Vickers hardness $\approx 100, \approx 10$ for organics), enable one to cut and polish them without any difficulty.

The possible use of the electro-optic (EO) properties of organic-inorganic crystals has not been assessed until now. The aim of this article is to present the EO measurements performed on single crystals of 2A5NPDP and 2A5NPDAs. Their efficiency for EO modulation is estimated via the calculation of figures of merit which depend, in part, on the EO coefficients.

Generally, two figures of merit $F_{1}$ and $V_{\pi}^{*}$ are considered for bulk crystal modulations [1]. The term $F_{1}=n^{7} r^{2} / \varepsilon$ is defined as the ratio of bandwidth to driving power (where the refractive index $n$, the EO coefficient $r$ and the dielectric permittivity $\varepsilon$ are effective parameters), whereas the reduced half-wave voltage $V_{\pi}^{*}$ corresponds to the voltage needed to obtain a $\pi$ retardation from a bulk material with a length $L$ (along the direction of laser beam propagation) equal to the thickness $d$ (along the direction of the applied electric field). A large efficiency for EO modulators therefore requires a large $F_{1}$ and a small $V_{\pi}^{*}$.

In addition, a crystal is really attractive for EO applications if it is nearly thermally insensitive. Indeed the ther- 
mooptic effect (TO) or a thermal change in the static birefringence $\Delta n_{0}$ can affect the performance of the EO device, in particular by a shift of the working point used for the modulation of the laser beam. Therefore a small variation of $\Delta n_{0}$, i.e. $\alpha=\delta \Delta n_{0} / \delta T$, in the crystal configuration used for EO modulation is desirable.

To combine the various characteristics required to achieve an efficient EO modulator, we define a new figure of merit $M=F_{1} / \alpha$, which should be as large as possible.

\section{Measurements and results}

Three main configurations with an electric field applied along the $c$-axis have been studied. Only these configurations are considered here since when the electric field is applied along the $a$-axis or $b$-axis, the EO coefficient is notably smaller. In each case, the effective EO coefficients $r_{a}, r_{b}$ and $r_{c}$ as well as the corresponding TO coefficients $\alpha_{a}, \alpha_{b}$ and $\alpha_{c}$ and the dielectric permittivity $\varepsilon_{c}$ have been measured.

The effective EO coefficients $r_{a}, r_{b}$ and $r_{c}$ are defined according to the orthorhombic Pna2 $2_{1}$ space group, when the light beam is propagating along the principal axis $a$ or $b$ or $c$, respectively. The corresponding field-induced birefringences in the $(b, c),(a, c)$ or $(a, b)$ plane are written as [8]:

$\Delta n_{b c}(E)=\frac{n_{b}^{3} r_{a} E}{2}, \Delta n_{a c}(E)=\frac{n_{a}^{3} r_{b} E}{2}, \Delta n_{a b}(E)=\frac{n_{a}^{3} r_{c} E}{2}$,

where $n_{a}, n_{b}$ and $n_{c}$ are the principal refractive indices.

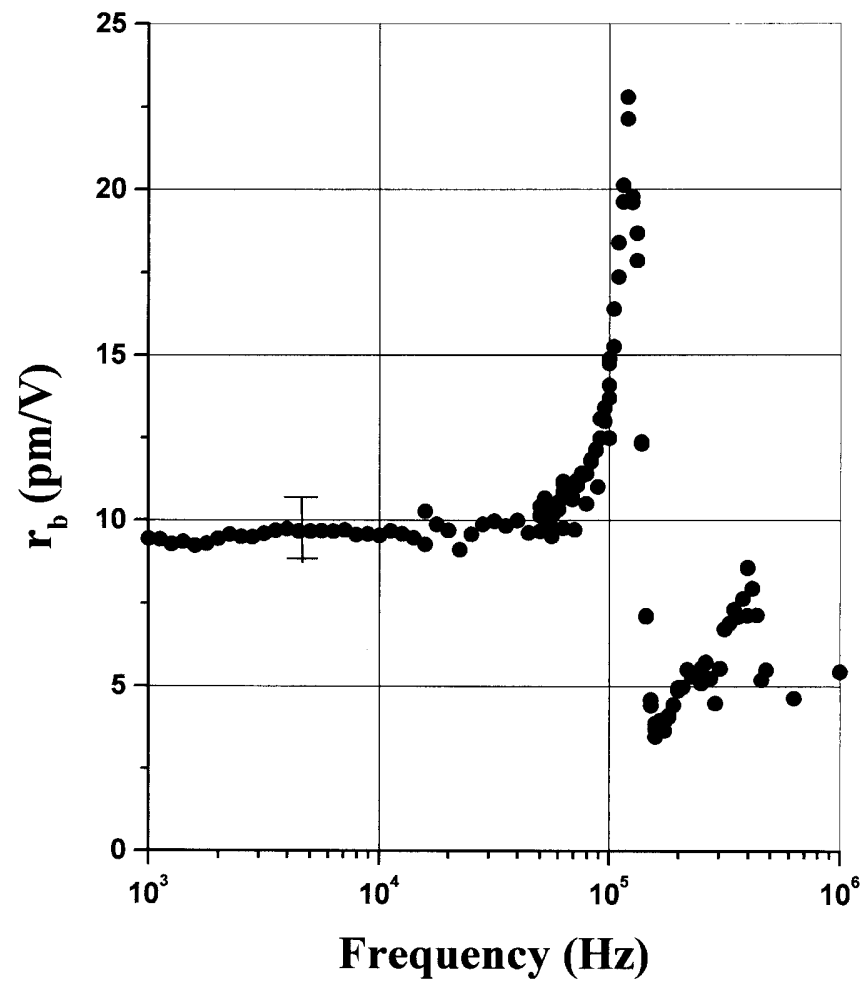

Fig. 1. Frequency dependence of the EO coefficient $r_{b}$ for 2A5NPDP ( $\lambda=$ $633 \mathrm{~nm}$ and $T=25^{\circ} \mathrm{C}$ ). The peaks at highest frequencies originate from the piezo-electric resonances in the crystal. A typical error bar associated to the measurements is also shown

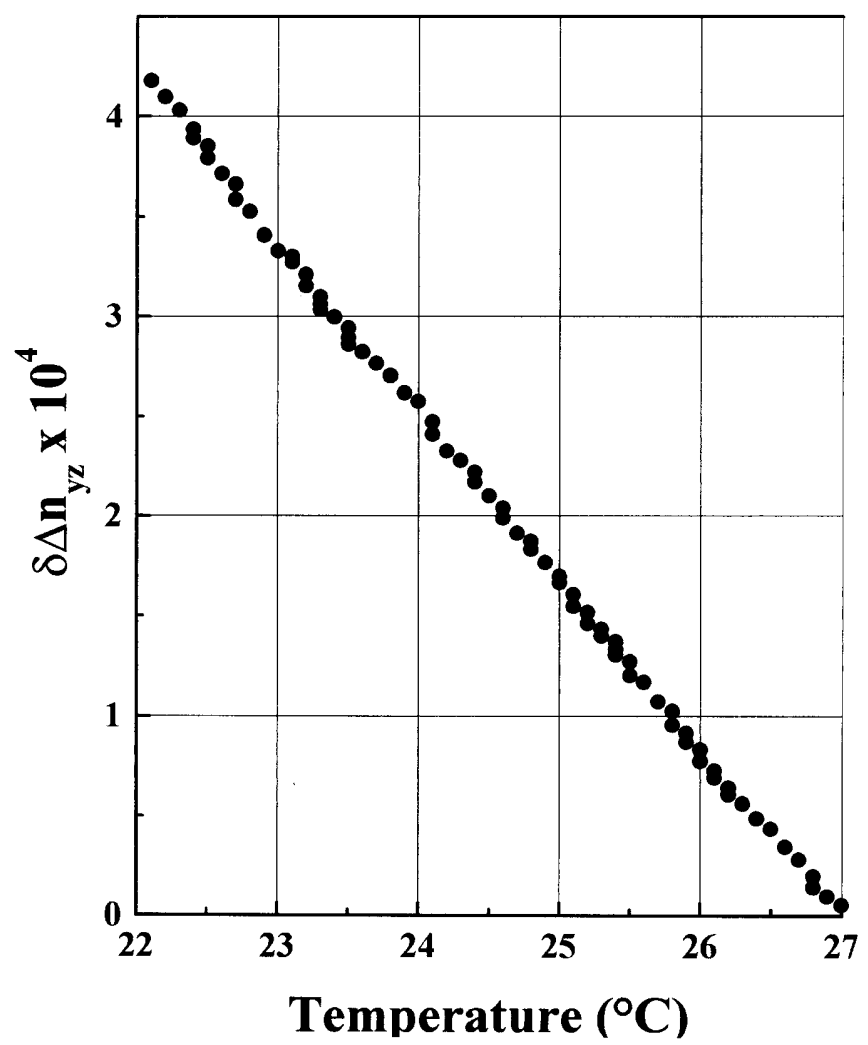

Fig. 2. Temperature dependence of the relative spontaneous birefringence $\Delta n_{b c}$ for 2A5NPDP $(\lambda=633 \mathrm{~nm})$. The slope gives the value of the thermooptic coefficient $\alpha_{a}$ which is equal to $8.5 \times 10^{-5}{ }^{\circ} \mathrm{C}^{-1}$

The EO coefficients were derived by the ac modulation technique based upon the Sénarmont setup [9]. The frequency dispersion of the EO coefficients was measured for modulation frequencies varying between $1 \mathrm{kHz}$ and $1 \mathrm{MHz}$ and using the $633 \mathrm{~nm}$ wavelength of a He-Ne laser. The amplitude of the ac voltage was $130 \mathrm{~V}$. Dielectric permittivity measurements were performed using a HP 4092 impedance analyzer with an amplitude voltage of $1 \mathrm{~V}$ and for frequencies varying from $1 \mathrm{kHz}$ up to $10 \mathrm{MHz}$. For all measurements, gold electrodes were evaporated on the surfaces of the samples.

Typical EO results obtained for the 2A5NPDP salt are shown in Fig. 1. The value of the EO coefficient $r_{b}$ of 2A5NPDP remains constant up to a frequency of $70 \mathrm{kHz}$, just below the first piezoelectric resonance. This behavior mainly reproduces the frequency dependence of the corresponding dielectric permittivity. The jump between low and high frequency values of $r_{b}$ can be attributed to a photoelastic contribution via the inverse piezoelectric effect.

The TO coefficients $\alpha_{a}, \alpha_{b}$ and $\alpha_{c}$, defined by:

$\alpha_{a}=\frac{\delta \Delta n_{b c}}{\delta T}, \alpha_{b}=\frac{\delta \Delta n_{a c}}{\delta T}, \alpha_{c}=\frac{\delta \Delta n_{a b}}{\delta T}$

are measured using the compensation of the phase shift method [10]. Figure 2 shows the variation of the spontaneous birefringence $\Delta n_{b c}$ in 2A5NPDP as a function of temperature. The results yield a linear temperature variation of the birefringence, with a slope of $\alpha_{a}=8.5 \times 10^{-5}{ }^{\circ} \mathrm{C}^{-1}$. 
Table 1. Effective electrooptic coefficients $r_{a}, r_{b}$ and $r_{c}$, dielectric permittivity $\varepsilon_{c}$ and thermooptic coefficients $\alpha_{a}, \alpha_{b}$ and $\alpha_{c}$ of 2A5NPDP and 2A5NPDAs obtained at room temperature for a modulation frequency equal to $1 \mathrm{kHz}$ and at a wavelength of $633 \mathrm{~nm}$

\begin{tabular}{|c|c|c|c|c|c|c|c|c|c|c|}
\hline \multirow[t]{2}{*}{ Crystals } & \multicolumn{3}{|c|}{$\begin{array}{l}\text { Effective electrooptic } \\
\text { coefficients /pm/V }\end{array}$} & \multicolumn{3}{|c|}{$\begin{array}{c}\text { Thermooptic } \\
\text { coefficients } / 10^{-5}{ }^{\circ} \mathrm{C}^{-1}\end{array}$} & \multirow{2}{*}{$\begin{array}{c}\text { Dielectric } \\
\text { permittivity } \\
\varepsilon_{c}\end{array}$} & \multicolumn{3}{|c|}{ Refractive indices } \\
\hline & $r_{a}$ & $r_{b}$ & $r_{c}$ & $\alpha_{a}$ & $\alpha_{b}$ & $\alpha_{c}$ & & $n_{a}$ & $n_{b}$ & $n_{c}$ \\
\hline 2A5NPDP & $11 \pm 1.2$ & $9.5 \pm 1$ & $0.3 \pm 0.04$ & $8.5 \pm 0.4$ & $11.3 \pm 0.5$ & $3 \pm 0.15$ & $6 \pm 0.2$ & 1.6115 & 1.6447 & 1.7373 \\
\hline 2A5NPDAs & $11 \pm 1.2$ & $8 \pm 0.9$ & $1.7 \pm 0.2$ & $8.9 \pm 0.4$ & $9.3 \pm 0.5$ & $0.3 \pm 0.02$ & $7.1 \pm 0.3$ & 1.6295 & 1.6669 & 1.7585 \\
\hline
\end{tabular}

Table 2. Figures of merit $F_{1}=n^{7} r^{2} / \varepsilon, V_{\pi}^{*}=\lambda / n^{3} r$ and $M=\left(n^{7} r^{2}\right) /(\varepsilon \alpha)$ of organic-inorganic 2A5NPDP $\left(r_{a}\right)$ and 2 A5NPDAs $\left(r_{a}\right)$ compared to those of inorganic $\mathrm{ADP}\left(r_{41}\right)$ and $\mathrm{LiNbO}_{3}\left(r_{c}\right)$ and organic NPP $\left(r_{12}\right)$ in their best configuration, for a modulation frequency of $1 \mathrm{kHz}$ and at a $633 \mathrm{~nm}$ wavelength

\begin{tabular}{cccc}
\hline Crystals & $F_{1} / \mathrm{pm}^{2} / \mathrm{V}^{2}$ & $V_{\pi}^{*} / \mathrm{V}$ & $M / \mathrm{pm}^{2} \mathrm{~K} \mathrm{~V}^{-2} \times 10^{6}$ \\
\hline 2A5NPDP & 568 & 13760 & 7.7 \\
2A5NPDAs & 520 & 13300 & 6.9 \\
$\mathrm{ADP}$ & 109.6 & 9860 & 3.51 \\
$\mathrm{LiNbO}_{3}$ & 3325 & 2972 & 81 \\
$\mathrm{NPP}$ & 2261 & 10269 & - \\
\hline
\end{tabular}

\section{Discussion}

The results obtained for both compounds, 2A5NPDP and 2A5NPDAs, are summarized in Table 1 , as are the values of refractive indices [11] $n_{a}, n_{b}, n_{c}$. For both phosphate and arsenate crystals, we notice that the EO and TO coefficients related to the birefringences $\Delta n_{a c}\left(r_{b}, \alpha_{b}\right)$ and $\Delta n_{b c}\left(r_{a}, \alpha_{a}\right)$ are much larger than the coefficients involving the birefringence $\Delta n_{a b}\left(r_{c}, \alpha_{c}\right)$. Moreover, the former coefficients are very similar to each other for both compounds. This could be attributed to the dominant contribution of the polarizability of the 2A5NP molecule, the dipole of which is mostly aligned along the $c$-axis. In the last configuration, the contribution of the chromophore is reduced because of its orientation and the discrepancy between the EO coefficient $r_{c}$ and the TO coefficient $\alpha_{c}$ reflects the difference in the contribution of the inorganic group $\left(\mathrm{H}_{2} \mathrm{XO}_{4}^{-}\right)(\mathrm{X}=\mathrm{P}, \mathrm{As})$ to the different properties.

The values of the figures of merit of 2A5NPDP and 2A5NPDAs were calculated from the values listed in Table 1 and compared to those of inorganic ADP [9] and $\mathrm{LiNbO}_{3}$ [12] and organic NPP [13] crystals (Table 2). 2A5NPDP and 2A5NPDAs are promising for use in EO modulation applications, considering the figure of merit $M$, which accounts for all needed characteristics, although the half-wave voltage is relatively large compared to that of materials commonly inserted in EO bulk modulators (ADP, $\left.\mathrm{LiNbO}_{3}\right)$. Furthermore, the dispersion of the EO coefficients (Fig. 1) limits the use of these compounds above or below the piezoelectric resonance frequencies. This is probably related to the mineral group bonded to the organic molecule and can constitute a general limitation to the use of organic-inorganic crystals in EO applications. In contrast, the influence of the mineral group at high (optical) frequencies should probably be very small so that the efficiency of the molecule for nonlinear optical applications is preserved in the organic-inorganic crystals [5]. Additional studies to investigate the respective influence of mineral and organic groups are currently in progress. It is also interesting to note that inorganic-organic 2A5NPDP and 2A5NPDAs crystals exhibit a value of the EO figure of merit $V_{\pi}^{*}$ comparable to that of pure organic crystal NPP which is based on the same chromophore (nitropyridium) but without having the disadvantages of molecular crystals (thermal, mechanical instabilities, low optical damage threshold, UV absorption).

\section{Conclusion}

This new approach of crystal engineering based on the anchorage of organic molecules exhibiting a large NLO efficiency to mineral groups, seems to be very promising for EO applications in view of the first results reported here and due to the large number of possible combinations of organic and inorganic parts. For instance, calculations performed on another organic-inorganic salt based on the same chromophore $(2 \mathrm{~A} 5 \mathrm{NPCl})$ showed that the charge transfer of the $2 \mathrm{~A} 5 \mathrm{NP}$ molecule is significantly enhanced by the presence of the highly electronegative $\mathrm{Cl}^{-}$anion [14] and could thus lead to an enhancement of the EO properties.

Acknowledgements. We are grateful to the Groupement de Recherche 1181 "Matériaux pour l'Optique Nonlinéaire" du Centre National de la Recherche Scientifique for its support for this study.

\section{References}

1. P. Günter (ed.): Electro-optic and photorefractive materials (Springer, Berlin 1987)

2. A. Ibanez, J.P. Levy, C. Mouget, E. Prieur: J. Solid State Chem. 129, 22 (1997)

3. J. Zaccaro, B. Capelle, A. Ibanez: J. Cryst. Growth 180, 229 (1997)

4. J. Zaccaro, M. Bagieu-Beucher, J. Espeso, A. Ibanez: J. Cryst. Growth 186, 224 (1998)

5. Z. Kotler, R. Hierle, D. Josse, J. Zyss, R. Masse: J. Opt. Soc. Am. B 9, 534 (1992)

6. R. Masse, J. Zyss: Mol. Eng. 1, 141 (1991)

7. J. Pecaut, Y. Lefur, R. Masse: Acta Crystallogr., B 49, 535 (1993)

8. P. Günter: Opt. Commun. 11, 285 (1974)

9. J.P. Salvestrini, M.D. Fontana, B. Wyncke, F. Brehat: Nonlin. Opt. 17, 271 (1997)

10. N.G. Theofanous, M. Aillerie, M.D. Fontana, G.E. Alexakis: Rev. Sci. Instrum. 68, 2138 (1997)

11. J.P. Feve, B. Boulanger, I. Rousseau, G. Marnier, J. Zaccaro, A. Ibanez: submitted to IEEE

12. M. Aillerie, M.D. Fontana, F. Abdi, C. Carabatos-Nedelec, N. Theofanous, G. Alexakis: J. Appl. Phys. 65, 2406 (1989)

13. J.W. Doane: Mater. Res. Bull. 16, 22 (1991)

14. J.F. Nicoud, R. Masse, C. Bourgogne, C. Evans: J. Mater. Chem. 7, 35 (1997) 